15

\title{
Активация гидрида магния прессованием с каталитическими добавками
}

\author{
() И.В. Шикин, Д.И. Елец, А.П. Войт, И.Е. Габис
}

Санкт-Петербургский государственный университет, Старый Петергоф

E-mail: shikin_ilya@mail.ru

Поступило в Редакцию 13 октября 2016 г.

Исследована активация разложения гидрида магния методом прессования с катализатором. Показано, что прессование приводит к образованию металлических зародышей, способствующих снижению температурного порога разложения гидрида магния. Установлено, что введение добавок снижает температуру дегидрирования. Наиболее эффективной оказалась добавка никелевого порошка.

DOI: 10.21883/PJTF.2017.04.44293.16521

Проблемы хранения и транспортировки водорода являются важными задачами в продвижении водородных энергетических технологий в области транспорта. Одним из наиболее перспективных металлов накопителей водорода является магний, он довольно дешевый, так как большое количество содержится в земной коре, и его гидрид способен содержать до 7.6\% массовой доли водорода. Гидрид магния представляет собой легкий нетоксичный порошок, безопасный для человека и окружающей среды. Синтез $\mathrm{MgH}_{2}$ возможен путем прямого гидрирования магниевого порошка.

К недостаткам гидрида магния следует отнести высокую температуру выделения и поглощения водорода (порядка $400-450^{\circ} \mathrm{C}$ ). Это обстоятельство, видимо, не позволит применять его в мобильных приложениях, однако перспективы использования этого материала в стационарных хранилищах водорода велики. Мало того, уже имеются примеры успешного использования гидрида магния в демонстрационных [1] и модульных промышленных [2-4] аккумуляторах водорода. В этих устройствах температура гидридного материала поддерживается достаточно высокой для протекания процессов сорбции и десорбции водорода. Использование эффективной термоизоляции не исключает тем не менее необходимости энергозатрат на поддержание высокой 
температуры. В связи с этим снижение температур выделения и поглощения водорода гидридом магния является важной задачей.

Активация, или снижение температур гидрирования и дегидрирования $\mathrm{MgH}_{2}$, может быть достигнута несколькими методами, абсолютным приоритетом среди которых обладает помол материала в шаровых мельницах с каталитическими добавками, часто в атмосфере водорода [2-6]. Именно таким способом активировался гидрид магния для уже упомянутых демонстрационных [1] аккумуляторов водорода [7-11]. Отмечается, однако, что этот путь не всегда приводит к положительным результатам [9]. Помимо этого имеется трудность масштабирования процесса, поскольку получаемые материалы имеют тенденцию к самовозгоранию на воздухе. В более масштабном проекте „адиабатического резервуара“ [12], успешно осуществленном компанией McPhy Energy, рабочим материалом являются диски из обработанного в шаровой мельнице в инертной атмосфере гидрида магния с добавлением графита, компактированного с патентованными добавками фирмы. Добавки графита призваны улучшить циклическую (сорбция-десорбция) устойчивость материала.

Известными альтернативными способами активирующих воздействий на металлогидридные материалы являются холодная ковка и прокатка. Холодная ковка $\mathrm{MgH}_{2}$ проводилась без каталитических добавок и показала увеличение скорости выделения водорода [13]. Холодная прокатка $\mathrm{MgH}_{2}$ [14] осуществлялась с добавками различных оксидов. Проводилось сравнение с шаровым помолом с теми же добавками и обнаружено, что шаровой помол более эффективно улучшает кинетику выделения водорода. Холодные ковка и прокатка этого же материала с добавками порошка железа [15] приводили к синтезу наноматериала с улучшенными десорбционными свойствами водорода. Отмечается, что предлагаемые процедуры механического воздействия существенно более просты, чем помол в шаровой мельнице.

В данной работе мы описываем еще один подход к активации гидрида магния - прессование материала на воздухе с каталитическими добавками. Будет показано, что его применение приводит к снижению температуры выделения водорода. Процедура прессования по сравнению с шаровым помолом довольно проста, получаемый материал не склонен к самовозгоранию на воздухе. В то же время по сравнению с ковкой она позволяет вести процесс более контролируемым образом.

2* Письма в ЖТФ, 2017, том 43, вып. 4 
Образцы гидрида магния были получены в данной работе путем прямого гидрирования в автоклаве мелкодисперсного магниевого порошка марки МПФ-4 чистотой 99.2\% при давлении водорода 100-120 atm и температуре $450^{\circ} \mathrm{C}$.

По мере того как происходило гидрирование, давление в автоклаве спадало. В таком состоянии порошок выдерживался около суток. По уровню спада давления определялось количество прореагировавшего водорода и, следовательно, стехиометрия полученного гидрида. В нашем случае получилось $7.5 \%$ массовой доли водорода в магнии для $\mathrm{MgH}_{2}$.

Колба с гидридом магния вскрывалась в перчаточном боксе, в среде инертного газа (азота) и там же фасовалась малыми порциями в контейнеры. После этого контейнеры помещались в эксикатор и хранились в нем при комнатной температуре.

Установка для исследования кинетики разложения гидридов представляла собой цельнометаллическую высоковакуумную систему, включавшую в себя систему откачки, систему напуска водорода и рабочую камеру, в которой находился исследуемый образец. Вся система откачки обеспечивала в рабочей части установки получение вакуума порядка $10^{-5}$ Torr. Измерение давления в установке производилось с помощью емкостных датчиков MKS. Исследуемые образцы помещались в автоклав, который устанавливался на вакуумную установку. После откачивания рабочего объема, с помощью Ті-геттера напускался водород давлением порядка 50 Torr для улучшения теплообмена в автоклаве. Выделение водорода из образцов фиксировалось по повышению давления в рабочей камере. Когда давление достигало некоторой постоянной отметки, это означало, что разложение закончилось. Количество выделенного водорода вычислялось из разности давлений до начала выделения и после его окончания.

Автоклав, куда засыпался исследуемый образец, представлял собой трубку из нержавеющей стали с внешним диаметром $6 \mathrm{~mm}$ и толщиной стенок $1.5 \mathrm{~mm}$, заваренную с одного конца, а другим концом вваренную во фланец. Фланец монтировался таким образом, что объем автоклава мог отсекаться от остальной установки вентилем. На трубку одевалась цилиндрическая печка. Нагрев до заданной температуры с заданной скоростью осуществлялся под контролем ЭВМ. Датчиком температуры служила хромель-алюмелевая термопара, приваренная к автоклаву с внешней стороны. С целью предотвращения нагревания остальных

Письма в ЖТФ, 2017, том 43, вып. 4 


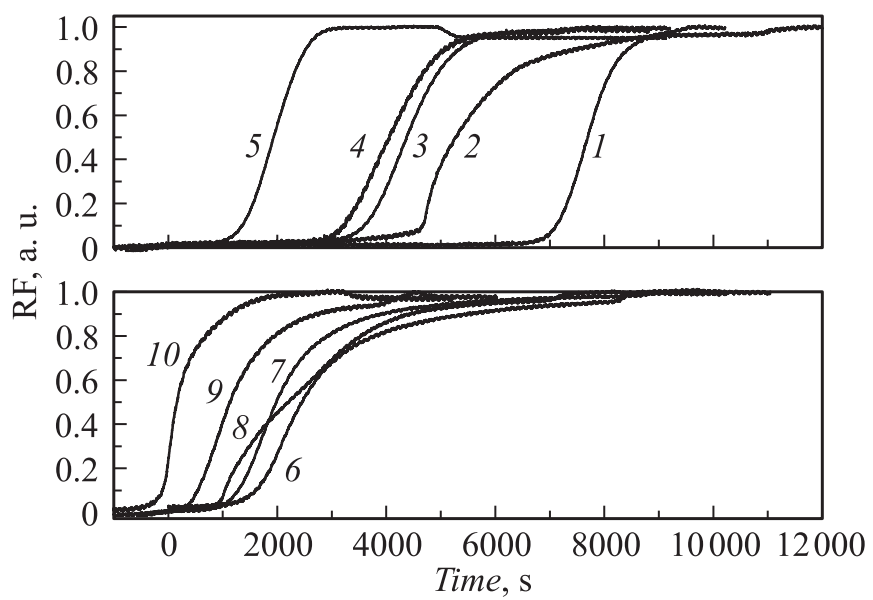

Рис. 1. Доля металлической фазы при выделении водорода из непрессованного (вверху) и прессованного (внизу) гидрида магния с разными катализаторами

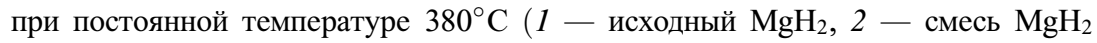
с углеродом, 3 - смесь $\mathrm{MgH}_{2}$ с $\mathrm{Mg}, 4-$ смесь $\mathrm{MgH}_{2}$ с Al, 5 - смесь $\mathrm{MgH}_{2}$ с Ni, 6 - прессованный $\mathrm{MgH}_{2}$ с $\mathrm{Mg}, 7$ - прессованный $\mathrm{MgH}_{2}$, 8 - прессованный $\mathrm{MgH}_{2}$ с углеродом, 9 - прессованный $\mathrm{MgH}_{2}$ с $\mathrm{Al}, 10-$ прессованный $\mathrm{MgH}_{2}$ с Ni).

частей установки, в особенности датчиков давления, печка закрывалась металлическим экраном.

Были проведены исследования влияния величины усилий гидравлического пресса на образцы гидрида магния. Они показали, что результаты, полученные при сжатии давлением более 3 тонн/ $\mathrm{cm}^{2}$, практически совпадают. Вследствие этого для проведения дальнейших экспериментов было выбрано усилие в 3 тонн/ $/ \mathrm{cm}^{2}$.

Из наших экспериментов, проведенных ранее [16], известно, что металлические вкрапления в гидрид магния снижают температуру его разложения и ускоряют его кинетику. Поэтому очень важен подбор материала пуансонов, между которыми прессовались исследуемые образцы и которые позволили бы нам исключить возможное появление со стороны пуансонов металлических вкраплений при подготовке прессованного гидрида магния. В качестве материалов были рассмотрены стальные

Письма в ЖТФ, 2017, том 43, вып. 4 
и стеклянные пластины, а также медная фольга. Стекло, очевидно, является абсолютно пассивным материалом и послужило репером пассивности пуансонов. Существенного влияния на воспроизводимость результатов экспериментов данные материалы не имели, поэтому мы остановились на закаленных пластинах из стали ст. 20 твердостью $420 \mathrm{HB}$.

В качестве каталитических добавок нами были выбраны следующие материалы: никель, алюминий, магний, углерод. Они смешивались с исходным гидридом магния. Была проведена серия экспериментов по изотермическому дегидрированию непрессованной смеси различных веществ с гидридом магния и прессованной смеси. Образцы нагревались до $380^{\circ} \mathrm{C}$ со скоростью $0.2^{\circ} \mathrm{C} / \mathrm{s}$ и выдерживались при этой температуре до полного выделения водорода. Результаты полученных исследований приведены на рис. 1. За начало отсчета брался момент, когда температура автоклава достигала значения $380^{\circ} \mathrm{C}$. По оси $Y$ отложена доля металлической фазы в образцах, при условии, что при 0 имеем исходный гидрид магния без металлической фазы.

На представленных графиках видно, что добавление различных катализаторов к гидриду магния приводит к более раннему началу десорбции водорода из образцов, причем добавление никеля существенно ускоряет выход по сравнению с исходным образцом гидрида магния (исходный гидрид магния начинает выделять водород через $6000 \mathrm{~s}$ после достижения температуры $380^{\circ} \mathrm{C}$, смесь с углем начинает выделять водород через $4500 \mathrm{~s}$, смесь с магнием - через $3500 \mathrm{~s}$, смесь с алюминием - через $3000 \mathrm{~s}$, а с никелем - через $1000 \mathrm{~s}$ ).

Прессование смеси гидрида магния с никелем увеличивает скорость выделения водорода из образцов, что можно заметить по форме полученных кривых. Кривая 10 (прессованная смесь гидрида магния с никелем) имеет более раннее начало и более крутой фронт, нежели кривая 5 (непрессованная смесь гидрида магния с никелем). В результате мы получили следующие зависимости: добавление различных катализаторов, а в особенности никеля, приводит к активации гидрида магния, а прессование с никелем приводит к существенному ускорению выхода водорода из гидрида магния.

Для более наглядного подтверждения полученных результатов были проведены эксперименты по дегидрированию образцов гидрида магния, прессованного гидрида магния, смеси гидрида магния с никелем и прессованного гидрида магния с никелем путем линейного нагрева (рис. 2). Нагрев проводился от 20 до $280^{\circ} \mathrm{C}$ со скоростью $0.5^{\circ} \mathrm{C} / \mathrm{s}$

Письма в ЖТФ, 2017, том 43, вып. 4 


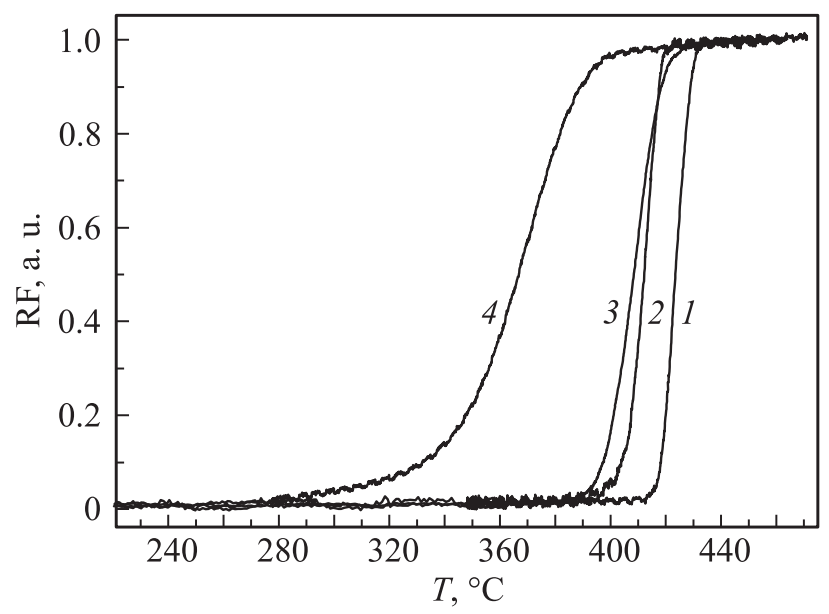

Рис. 2. Доля металлической фазы при выделении водорода из непрессованного и прессованного гидрида магния с $\mathrm{Ni}$ при линейном нагреве до $470^{\circ} \mathrm{C}$ (1 - исходный $\mathrm{MgH}_{2}, 2$ - смесь $\mathrm{MgH}_{2}$ с $\mathrm{Ni}, 3$ - прессованный $\mathrm{MgH}_{2}$, 4 - прессованный $\mathrm{MgH}_{2}$ с Ni).

для ускорения процесса проведения эксперимента (температура $280^{\circ} \mathrm{C}$ была выбрана из-за раннего начала выделения водорода из образцов прессованного гидрида магния с никелем), а от 280 до $470^{\circ} \mathrm{C}$ - со скоростью $0.05^{\circ} \mathrm{C} / \mathrm{s}$.

Из рис. 2 видно, что механическая активация (с использованием гидравлического пресса) и добавление катализатора (никеля) приводит к снижению температурного порога разложения гидрида магния.

Для объяснения полученных результатов был проведен рентгенофазовый анализ двух образцов гидрида магния: исходного и прессованного, который показал, что при прессовании часть водорода выделяется, тем самым образуя на поверхности зародыши металлического магния, благодаря которым существенно увеличивается скорость десорбции водорода. Добавление металлической фазы к гидриду магния или образование металлических зародышей в гидридной фазе вещества способствует улучшению кинетики выделения водорода из гидридов, что также было показано в работах [16-18] на примере гидридов алюминия и магния.

Письма в ЖТФ, 2017, том 43, вып. 4 
Таким образом, в результате проделанной работы нами показали, что прессование с катализатором является эффективным способом механической активации гидрида магния, который не требует больших энергетических и временных затрат, и установлено, что введение добавок, а особенно никеля, приводит к активации разложения гидрида магния. Прессование гидрида магния приводит к образованию металлических зародышей, способствующих снижению температурного порога его разложения, а добавка никеля при прессовании улучшает десорбционные свойства гидрида, необходимые для практического применения.

Работа была выполнена при поддержке Российского фонда фундаментальных исследований (грант № 16-08-01244 А).

Авторы благодарят за помощь в подготовке работы ресурсный центр „Рентгенодифракционные методы исследования“ и МРЦ „Нанотехнологии“ Санкт-Петербургского государственного университета.

\section{Список литературы}

[1] Yartys V.A., Lototsky M.V., Maehlen J.P. // Review, ENSYS, IFE. 2005.

[2] Baptiste Delhomme, Patricia de Rango, Philippe Marty et al. // Int. J. Hydrogen Energy. 2012. V. 37. P. 9103-9111.

[3] Chaise A., de Rango P., Marty Ph., Fruchart D. // Int. J. Hydrogen Energy. 2010. V. 35. P. 6311-6322.

[4] de Rango P., Chaise A., Charbonnier J. et al. // J. Alloys Compd. 2007. V. 446 447. P. $52-57$.

[5] Borisov D.N., Fursikov P.V., Tarasov B.P. // Int. J. Hydrogen Energy. 2011. V. 36. Iss. 1. P. 1326-1329.

[6] Løken S., Solberg J.K., Maehlen J.P. et al. // J. Alloys Compd. 2007. V. 446-447. P. $114-120$.

[7] Wu Y., Lototsky M.V., Solberg J.K., Yartys V.A. // J. Alloys Compd. 2011. V. 509. P. S640-S645.

[8] Wu Y., Lototskyy M.V., Solberg J.K., Yartys V.A. // Int. J. Hydrogen Energy. 2012. V. 37. P. $1495-1508$.

[9] Williams M., Sibanyoni J.M., Lototskyy M., Pollet B.G. // J. Alloys Compd. 2013. V. 580. P. S144-S148.

[10] Lototskyy M., Sibanyoni J.M., Denys R.V. et al. // Carbon. 2013. V. 57. P. 146160.

[11] Lototsky M., Davids M.W., Sibanyoni J.M. et al. // J. Alloys Compd. 2015. V. 645. P. S454-S459.

Письма в ЖТФ, 2017, том 43, вып. 4 
[12] Michel Jehan, Daniel Fruchart // J. Alloys Compd. 2013. V. 580. P. S343-S348.

[13] Alexandre Augusto Cesario Asselli, Daniel Rodrigo Leiva, Gustavo Henrique Cozentino et al. // J. Alloys Compd. 2014. V. 615. P. S719-S724.

[14] Bellemare J., Huot J. // J. Alloys Compd. 2012. V. 512. P. 33-38.

[15] Leiva D.R., Floriano R., Huot J. et al. // J. Alloys Compd. 2011. V. 509. P. S444S448.

[16] Evard E., Gabis I., Yartys V.A. // J. Hydrogen Energy. 2010. V. 35. P. 9060-9069.

[17] Gabis I.E., Chernov I.A., Voyt A.P. // J. Alloys Compd. 2013. V. 580. Suppl. 1. P. S243-S246. SI: MH2012.

[18] Gabis I., Dobrotvorskiy M., Evard E., Voyt A. // J. Alloys Compd. 2011. V. 509. Suppl. 2. P. S671-S674. Proceedings of the 12th International Symposium on Metal-Hydrogen Systems, Fundamentals and Applications (MH2010).

Письма в ЖТФ, 2017, том 43, вып. 4 